\title{
Stress analysis of divertor plasma-facing component designs using tungsten particle-reinforced copper composite heat sink
}

\author{
Kuo Zhang ${ }^{\mathrm{a}}$, Alexander von Müller ${ }^{\mathrm{a}, \mathrm{b}}$, Henri Greuner ${ }^{\mathrm{a}}$, Jeong-Ha You ${ }^{\mathrm{a}}$ \\ ${ }^{a}$ Max Planck Institute for Plasma Physics, Boltzmannstraße 2, 85748 Garching, Germany \\ ${ }^{b}$ Technische Universität München, 85748 Garching, Germany
}

The $\mathrm{W}-\mathrm{Cu}$ composites are considered as advanced heat sink material for plasma-facing components, depending notably on the reduced macroscopic coefficient of thermal expansion compared with monotonic $\mathrm{Cu}$ materials. One class of such W$\mathrm{Cu}$ composite materials is $\mathrm{W}$ particle-reinforced $\mathrm{Cu}$ composites which can be joined to pure tungsten parts as plasmafacing armor. After heat flux tests with $20 \mathrm{MW} / \mathrm{m}^{2}$ and with a target of 500 cycles, it is found that fracture occurred after around 100 cycles either on the side of $\mathrm{W}$-armor or on the interface between $\mathrm{W}$-armor and W-Cu composite heat sink. In this work, the stress as well as temperature processes during the cyclic heat flux loadings have been investigated with finite-element method for two designs with $\mathrm{W}-\mathrm{Cu}$ composite materials, and compared with the former design with $\mathrm{W}$ armor and $\mathrm{CuCrZr}$-heat sink. Possible causes for the fracture have been proposed.

Keywords: W-Cu composites; copper interface; cyclic stress

\section{Introduction}

Tungsten-copper $(\mathrm{W}-\mathrm{Cu})$ composite materials are currently considered as advanced heat sink materials for highly heat loaded plasma-facing components (PFCs). Design concepts of such $\mathrm{W}-\mathrm{Cu}$ composites are being investigated within the framework of the EUROfusion DEMO divertor project $[1,2]$.

One class of such materials are tungsten particlereinforced copper composites which can be joined to pure tungsten parts as plasma-facing armor [3]. Depending on the material composition, the composite materials exhibit notably reduced macroscopic coefficients of thermal expansion (CTE) compared with copper alloys such as $\mathrm{CuCrZr}$, which in turn reduces the thermally induced stresses within the components.

Two designs with $\mathrm{W}-\mathrm{Cu}$ composite materials have been evaluated. The first one is $\mathrm{W}$-armor directly joined to composite material with $30 \mathrm{wt} \% \mathrm{Cu}(\mathrm{W}-30 \% \mathrm{Cu})$ as heat sink (Fig.1-b). The other design has $1 \mathrm{~mm}$ thick composite material with $15 \mathrm{wt} \% \mathrm{Cu}(\mathrm{W}-15 \% \mathrm{Cu})$ between the $\mathrm{W}$-armor and $\mathrm{W}-30 \% \mathrm{Cu}-$ heat sink (Fig.1-c). Note that, this $1 \mathrm{~mm}$ interlayer has replaced $1 \mathrm{~mm} \mathrm{~W}-30 \% \mathrm{Cu}$. Comparison is done with the previous design based on W-armor and CuCrZr-heat sink (Fig.1-a).

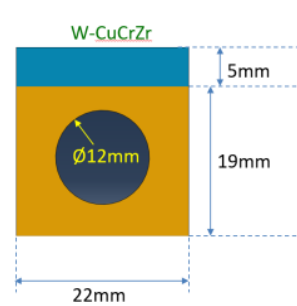

a)

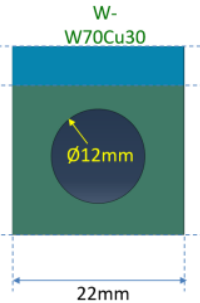

b)

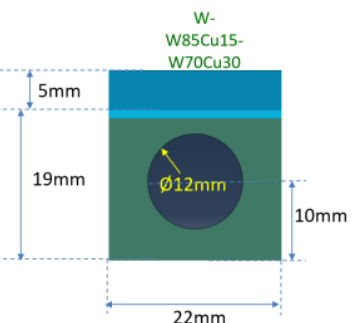

c)
Fig. 1. Sketches of three designs.

This work briefly introduces the performed heat flux tests, and focuses on the finite-element method (FEM) simulation for the investigation of the cause of fractures occurred during the heat flux tests.

\section{Material and experiment}

The tungsten particle-reinforced $\mathrm{Cu}$ composites have been introduced in [3, 4]. Various mechanical and physical properties of these composite materials have been presented.

These composite materials are joined to pure tungsten armor with pure copper interface. The microscopic images of one of the samples near the copper interface between $\mathrm{W}$-armor and $\mathrm{W}-30 \mathrm{wt} \% \mathrm{Cu}-$ heat sink are shown in Fig.2. The thickness of this pure copper interface is around $10 \mu \mathrm{m}$.
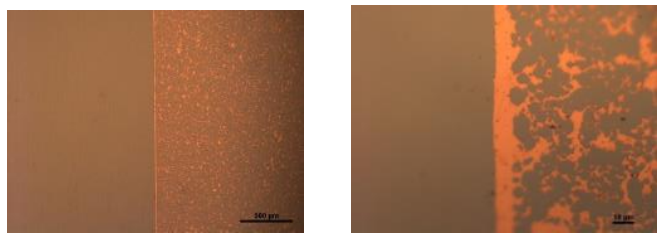

Fig. 2. Microscopic images of $\mathrm{W}$-armor joined to $\mathrm{W}$ particle-reinforced $\mathrm{Cu}$ composites with $30 \mathrm{wt} \% \mathrm{Cu}$. The scales are respectively $500 \mu \mathrm{m}$ (left) and $10 \mu \mathrm{m}$ (right).

After the heat flux tests performed in the GLADIS facility in the Max Planck Institute for Plasma Physics, fractures appear on the cyclic loaded samples. The tests have been performed with peak heat flux of $20 \mathrm{MW} / \mathrm{m}^{2}$ and with a target of 500 cycles. The samples have been heated up during 10 seconds, and cooled down to coolant temperature during another 10 seconds. This process has been repeated to realize cyclic heat flux loading.

The temperature of cooling water is $130^{\circ} \mathrm{C}$ with pressure $4 \mathrm{MPa}$ and speed $16 \mathrm{~m} / \mathrm{s}$. 
Images of samples after the GLADIS tests are shown in Fig.3. In some samples, as in Fig.3-a), the fractures appear on the sides of $\mathrm{W}$-armor near the interface to the heat sink. In some other samples, as in Fig.3-b), the fractures appear directly on the copper interface. No fracture is found on the plasma facing W surface, as in Fig.3-c).

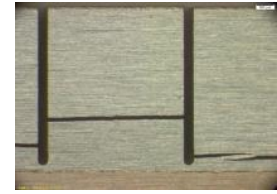

a)

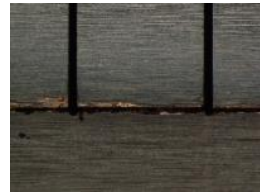

b)

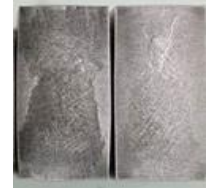

c)
Fig. 3. a) Fractures on the sides of W-armor near the interface. b) Fractures on the $\mathrm{Cu}$ interface. c) Plasma facing surface of the $\mathrm{W}$-armor.

\section{Temperature analysis with FEM}

As mentioned above, the temperature processes for the three designs have been simulated with FEM software. For each design, the temperatures at three points of interest have been analyzed. As shown in Fig.4, the three points are (1): The side of the plasma-facing surface of $\mathrm{W}$-armor, where the maximum temperature is located. (2): The side of the copper interface, where the fracture mostly appeared in the experiments. (3): The top of pipe-coolant interface, where high load and high temperature would appear in the heat sink.

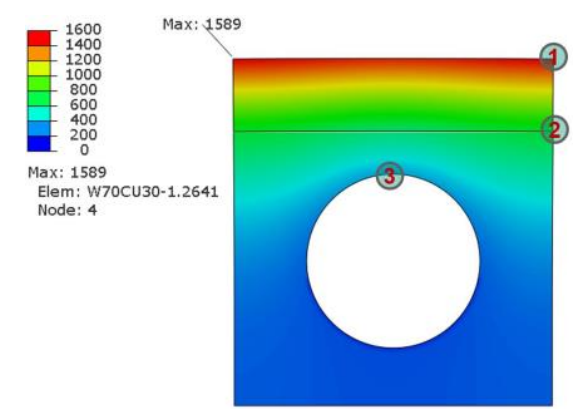

Fig. 4. Simulated temperature of a sample with $\mathrm{W}$-armor joined to W-30\%Cu-heat sink after 10 seconds of $20 \mathrm{MW} / \mathrm{m}^{2}$ heat flux loading, coolant temperature $130^{\circ} \mathrm{C}$.

For each position, the maximum temperature appears at the end of the heat loading phase. These temperatures are collected in the histograms in Fig.5. The application of $\mathrm{W}-\mathrm{Cu}$ composites has narrowly increased the temperatures at the top of pipe-coolant interface (point 3 , Fig.5-c).

For the plasma-facing surface (point 1, Fig.5-a) and the side of copper interface (point 2, Fig.5-b), the temperature increase is larger. According to the research of material properties of tungsten collected from [5-8], the temperature increase will reduce yield strength, and on the other hand, raise the fracture toughness.

The additional $1 \mathrm{~mm}$ interlayer of $\mathrm{W}-15 \% \mathrm{Cu}$ between the $\mathrm{W}$-armor and the $\mathrm{W}-30 \% \mathrm{Cu}$-heat sink leads to marginal difference in the temperatures at points 1 and 2 .
This difference of temperature at point 3 is even negligible.

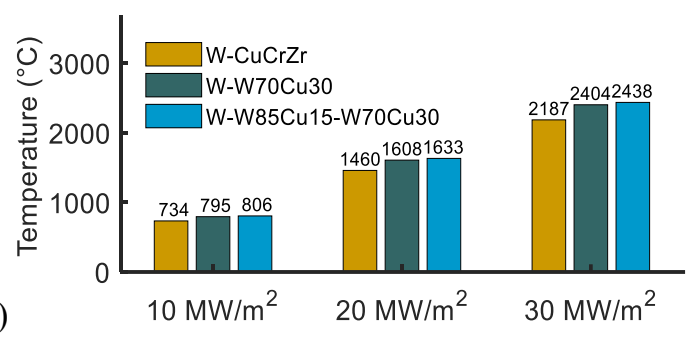

b)

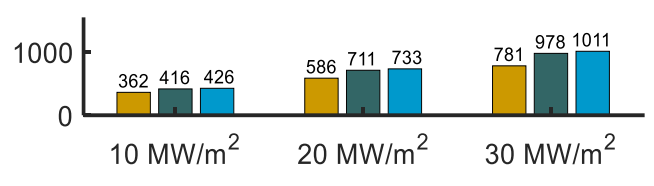

c)

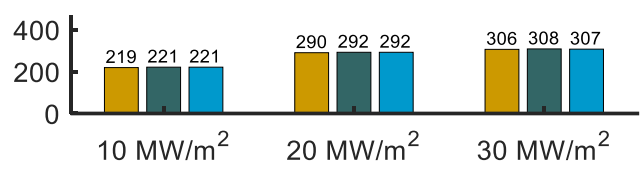

Fig. 5. Maximum temperatures during heat flux loadings at the three points of interest.

\section{Stress analysis with FEM}

With the purpose to reveal the cause for the fractures after the cyclic heat flux tests, a series of analyses have been performed in FEM software.

One of the analyses has adopted the temperature profile from the above mentioned temperature analysis for the design with $\mathrm{W}$-armor joined to $\mathrm{W}-30 \% \mathrm{Cu}$-heat sink, heat flux (HF) is $20 \mathrm{MW} / \mathrm{m}^{2}$ and coolant temperature is $130^{\circ} \mathrm{C}$. Due to different CTEs, there is offset between the $\mathrm{W}$-armor and $\mathrm{W}-30 \% \mathrm{Cu}$-heat sink near the copper interface. This offset is supposed to be the cause of fractures of the copper interface, as Fig.3-b).

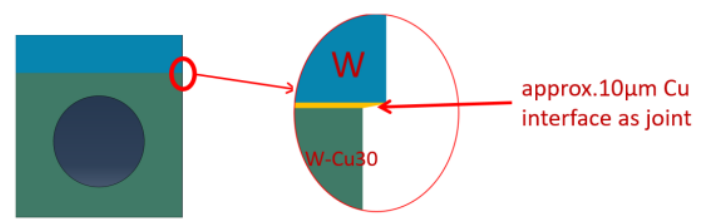

a) schematic drawing of the side of copper interface Simulated

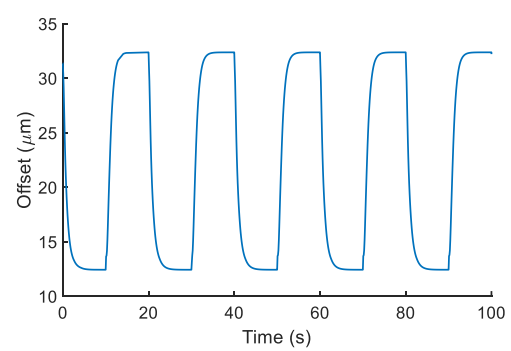

b) Offset of the corner of $\mathrm{W}$-armor and $\mathrm{W}-30 \% \mathrm{Cu}, 20 \mathrm{MW} / \mathrm{m}^{2}$.

Fig. 6. Simulation with $\mathrm{W}$-armor joined to $\mathrm{W}-30 \% \mathrm{Cu}$. 
Fig.6-a) shows the schematic drawing of the sample near the copper interface. The deformations of the corners of $\mathrm{W}$-armor and the $\mathrm{W}-30 \% \mathrm{Cu}$-heat sink are recorded to calculate the offset. As shown in Fig.6-b), the offset alternates between around 12 and $32 \mu \mathrm{m}$. Since the thickness of the copper interface is only around $10 \mu \mathrm{m}$, this massive cyclic deformation of the interface is considered to cause fractures.

Note that the initial offset of around $32 \mu \mathrm{m}$ is caused by fabrication, in which the sample is cooled from the stress-released state in high temperature to room temperature. In real fabrication, the samples are cooled from the melting point of copper, of around $1080^{\circ} \mathrm{C}$. However in the FEM simulation, since pure copper is already very soft at $600^{\circ} \mathrm{C}$ and the corresponding material properties over this temperature are lacking, the supposed stress-released state is set at $600^{\circ} \mathrm{C}$ for the simulation.

However, it has been found that, with this soft $10 \mu \mathrm{m}$ pure copper interface in the simulation, the thermally induced stress in $\mathrm{W}$-armor near the interface is negligible, which is no more than $50 \mathrm{MPa}$ during the whole heating-cooling process. If this were real in the experiments, there would be no fracture in tungsten armor as shown in Fig.3-a). For this reason, further FEM simulations have been performed with tungsten directly joined to the heat sink, without the copper interface.

Similar to temperature analysis, the stress analyses have been performed also on the three designs. The highest maximum principal stresses appeared during the first heating-cooling process have been located and recorded. For better illustration, the positions where the highest maximum principal stresses appear have been marked in the schematic drawings in Fig.7. The directions of these maximum principal stresses are illustrated with red arrows in Fig.7.
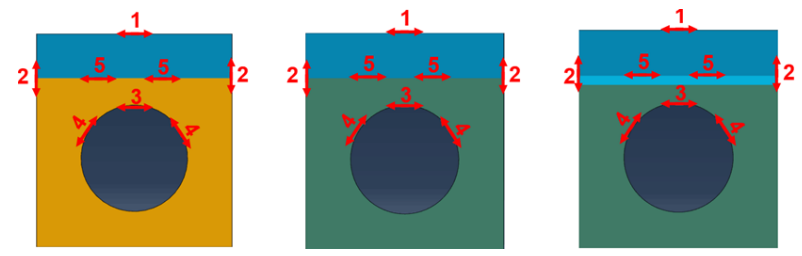

Fig. 7. Several points of interest are marked on the three designs. a) $\mathrm{W}$-armor joined to $\mathrm{CuCrZr}$ heat sink. b) $\mathrm{W}$-armor joined to $\mathrm{W}-30 \% \mathrm{Cu}$. c) $\mathrm{W}$-armor joined to $\mathrm{W}-30 \% \mathrm{Cu}$ with $1 \mathrm{~mm} \mathrm{~W}-15 \% \mathrm{Cu}$ interlayer.

The located and recorded maximum principal stresses are summarized in the histograms in Fig.8. On each bar, the red number indicates the position where the highest maximum principal stress is located during the heating-cooling process.

The application of $\mathrm{W}-\mathrm{Cu}$ composites has obviously reduced the thermally induced stress in $\mathrm{W}$-armor, however increased the stresses in the heat sink to an extent. The introduction of $1 \mathrm{~mm} \mathrm{~W}-15 \% \mathrm{Cu}$ interlayer between $\mathrm{W}$-armor and $\mathrm{W}-30 \% \mathrm{Cu}$-heat sink has marginally reduced the stresses in heat sink.

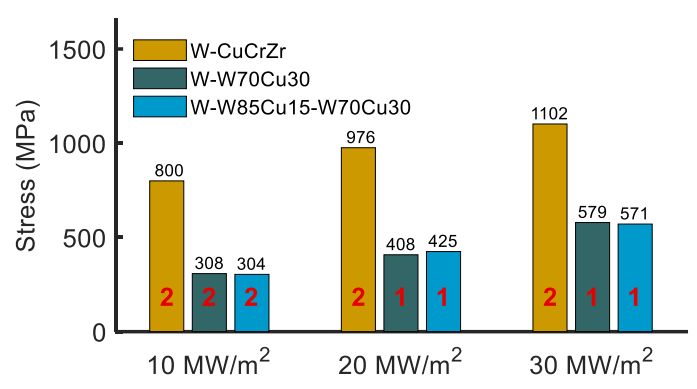

a) Max. principal stress in $\mathrm{W}$-armor

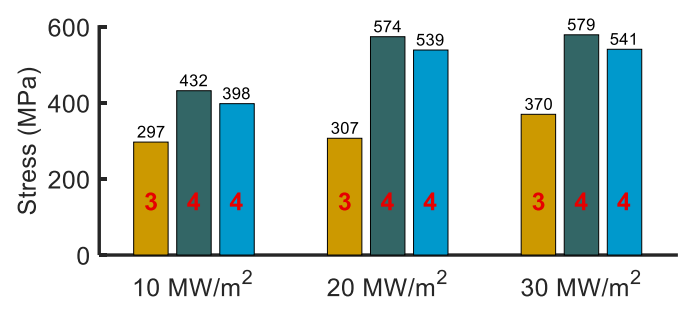

b) Max. principal stress in $\mathrm{CuCrZr}$ or $\mathrm{W}-30 \% \mathrm{Cu}$-heat sink

Fig. 8. Max. principal stresses.

Note that the position number " 2 " is not directly on the copper interface, but it is located somewhat above, and near the side of tungsten. Fig. 9 illustrates the stress distribution in $\mathrm{W}$-armor at the left side of the sample, at the beginning of the heating phase. The highest maximum principal stress is located above the copper interface. This simulated phenomenon corresponds to the fractures on the sides of $\mathrm{W}$-armor in HF experiments, as shown in Fig.3-a).

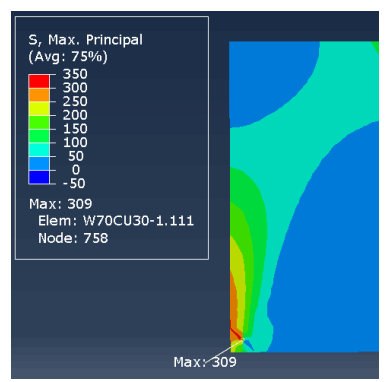

Fig. 9. Maximum principal stress on the $\mathrm{W}$-armor at the beginning of the $10 \mathrm{~s}$-heating phase. HF $20 \mathrm{MW} / \mathrm{m}^{2}$.

Further stress analyses have been performed with two FEM simulations: Heat fluxes are respectively 10 and 20 $\mathrm{MW} / \mathrm{m}^{2}$. These two simulations have been performed with more than three HF-loading cycles. 


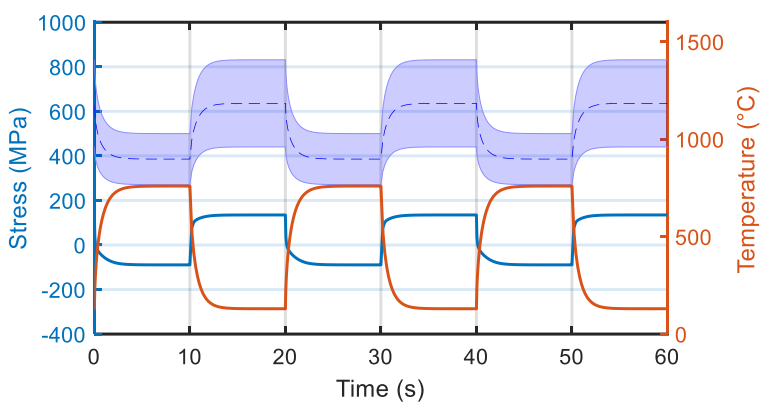

a) $10 \mathrm{MW} / \mathrm{m}^{2}$, position 1

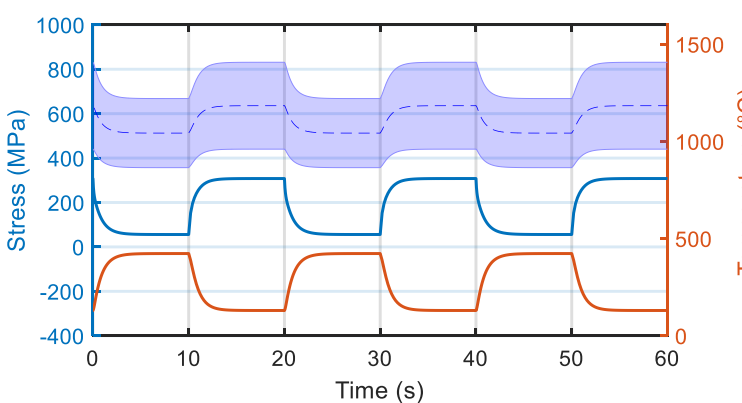

c) $10 \mathrm{MW} / \mathrm{m}^{2}$, position 2

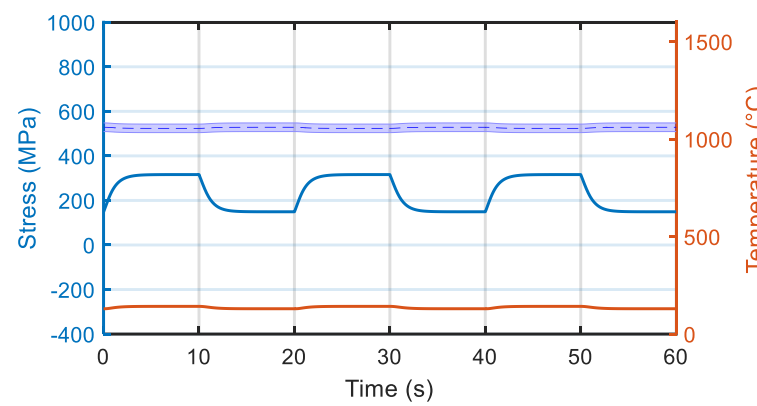

e) $10 \mathrm{MW} / \mathrm{m}^{2}$, position 4

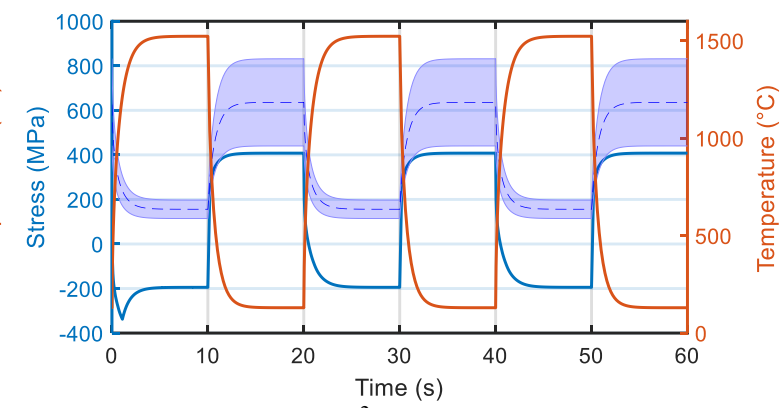

b) $20 \mathrm{MW} / \mathrm{m}^{2}$, position 1

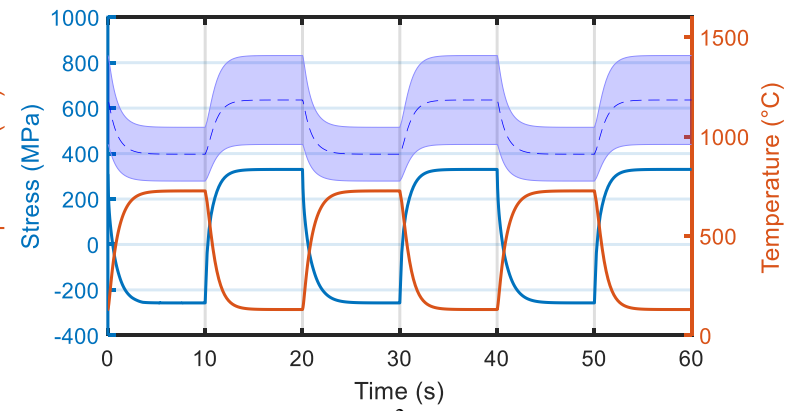

d) $20 \mathrm{MW} / \mathrm{m}^{2}$, position 2

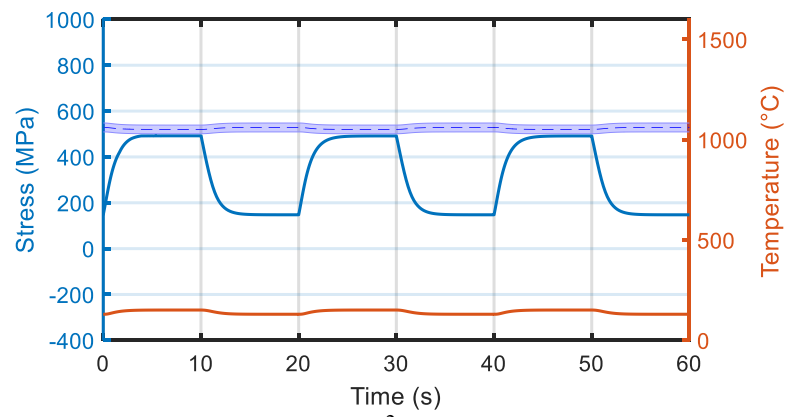

f) $20 \mathrm{MW} / \mathrm{m}^{2}$, position 4

Fig. 10. Stress and temperature process during the first three HF-loading cycles. Blue curves indicate

The maximum principal stresses and the corresponding temperatures as well as the calculated temperature-depended ultimate tensile strengths have been illustrated in the diagrams in Fig.10. For the HF 20 $\mathrm{MW} / \mathrm{m}^{2}$, the cyclic stress near the copper interface (position 2, Fig.10-d) has amplitude of around 300MPa with middle stress of 30MPa. Together with the analysis of location shown in Fig.9, such cyclic loading at position 2 is considered to be the cause of the fracture shown in Fig.3-a).

The amplitude of the cyclic stress at the plasmafacing surface (position 1) is also around 300MPa for the case with $\mathrm{HF} 20 \mathrm{MW} / \mathrm{m}^{2}$, and the middle stress is even larger $(100 \mathrm{MPa})$, comparing to around $30 \mathrm{MPa}$ at position 2. However, during the heating phase, when the temperature is at around $1500^{\circ} \mathrm{C}$, there is compressive plastic strain in the material according to the simulations. This is under the assumption that tungsten has the same absolute value of compressive yield strength as tensile yield strength. This explains why no fracture is observed on the plasma-facing surface.

For pipe-coolant interface, the highest maximum principal stresses always appear at positons number " 4 ", instead of the top (position 3). Hence, the stresses and temperatures are recorded for position 4 . Note that the exact angles of position 4 are different from case to case according to the FEM simulations. Although the ultimate tensile strength is narrowly above the highest stress for case with $\mathrm{HF} 20 \mathrm{MW} / \mathrm{m}^{2}$, as shown in Fig. 10-f), the amplitude of the cyclic stress is only around $170 \mathrm{MPa}$. This explains why no fracture is found on the pipecoolant interface. However, more material properties especially fatigue strengths of the $\mathrm{W}-\mathrm{Cu}$ composites are still missing for quantitative analysis.

For the cases with $\mathrm{HF} 10 \mathrm{MW} / \mathrm{m}^{2}$, the simulated maximum principal stresses are clearly below the temperature-depended ultimate tensile strength, despite the uncertainty of the material properties. Hence, the design with $\mathrm{W}$ particle-reinforced $\mathrm{Cu}$ composites is safe for lower heat fluxes e.g. $10 \mathrm{MW} / \mathrm{m}^{2}$.

\section{Discussion}

Two types of fractures have been observed after the cyclic heat flux tests, as shown respectively in Fig.3-a) and Fig.3-b). One type is located somewhere on the side of $\mathrm{W}$-armor and above the copper interface. The other type is located directly on the copper interface. 
According to the above mentioned FEM simulations, if there is copper interface between $\mathrm{W}$-armor and heat sink, the thermally induced stress in the W-armor near the side of copper interface is negligible and is considered not able to cause fracture at this position. However, if the copper interface is deleted and the Warmor is directly joined to the $\mathrm{W}-30 \% \mathrm{Cu}$ or $\mathrm{W}-15 \% \mathrm{Cu}$ composites, the stress alternates with high amplitudes and high middle stresses, which is considered to cause fracture after high number of cycles.

For this reason, it is suggested that in some samples such as the one shown in Fig.3-b), the copper interface is relatively thicker, which on one hand largely reduced the stress in $\mathrm{W}$-armor, however on the other hand caused massive deformation in copper. This phenomenon is considered the cause of fracture on copper interface.

On the contrary in some other samples such as the one shown in Fig.3-a), the copper interface is relatively thinner, which makes $\mathrm{W}$-armor directly joined to the $\mathrm{W}$ $\mathrm{Cu}$ composites. This is considered the cause of fracture on the side of $\mathrm{W}$-armor.

\section{Conclusion}

The application of $\mathrm{W}$ particle-reinforced $\mathrm{Cu}$ composites has largely reduced the thermally induced stress in W-armor, and however increased the stress in the heat sink to an extent.

The causes of the two types of fractures have been qualitatively evaluated. It is considered that, if the copper interface is relatively thicker, fractures appear directly on the interface. And if the copper interface is relatively thinner, fractures appear on $\mathrm{W}$-armor side near the copper interface.

Further evaluation is planned after more reliable material properties are available.

\section{Acknowledgement}

This work has been carried out within the framework of the EUROfusion Consortium and has received funding from the Euratom research and training programme 2014-2018 and 2019-2020 under grant agreement number 633053. The views and opinions expressed herein do not necessarily reflect those of the European Commission.

\section{References}

[1] J. H. You, E. Visca, C. Bachmann, T. Barrett, F. Crescenzi, M. Fursdon, et al., European DEMO divertor target: Operational requirements and material-design interface, Nuclear Materials and Energy, vol. 9, pp. 171-176, 2016.

[2] J. H. You, E. Visca, T. Barrett, B. Böswirth, F. Crescenzi, F. Domptail, et al., European divertor target concepts for DEMO: Design rationales and high heat flux performance, Nuclear Materials and Energy, vol. 16, pp. 1-11, 2018.
[3] A. v. Müller, D. Ewert, A. Galatanu, M. Milwich, R. Neu, J. Y. Pastor, et al., Melt infiltrated tungsten-copper composites as advanced heat sink materials for plasma facing components of future nuclear fusion devices, Fusion Engineering and Design, vol. 124, pp. 455-459, 2017.

[4] E. Tejado, A. v. Müller, J. H. You, and J. Y. Pastor, The thermo-mechanical behaviour of $\mathrm{W}-\mathrm{Cu}$ metal matrix composites for fusion heat sink applications: The influence of the $\mathrm{Cu}$ content, Journal of Nuclear Materials, vol. 498, pp. 468475, 2018.

[5] J. R. Stephens, Review of deformation behavior of tungsten at temperatures less than 0.2 absolute melting temperature, Lewis Research Center, Cleveland Ohio 44135, NASA Technical memorandum, 1972.

[6] M. Wirtz, J. Linke, T. Loewenhoff, G. Pintsuk, and I. Uytdenhouwen, Thermal shock tests to qualify different tungsten grades as plasma facing material, Physica Scripta, vol. T167, p. 014015, 2016.

[7] T. Hirai, S. Panayotis, V. Barabash, C. Amzallag, F. Escourbiac, A. Durocher, et al., Use of tungsten material for the ITER divertor, Nuclear Materials and Energy, vol. 9, pp. 616-622, 2016.

[8] R. E. Schmunk and G. E. Korth, Tensile and lowcycle fatigue measurements on cross-rolled tungsten, Journal of Nuclear Materials, vol. 103\&104, pp. 943-948, 1981. 